\title{
GLOBAL CLIMATOLOGIES OF EULERIAN AND LAGRANGIAN FLOW FEATURES BASED ON ERA-INTERIM
}

Michael Sprenger, Georgios Fragkoulidis, Hanin Binder, Mischa Croci-Maspoli, Pascal Graf, Christian M. Grams, Peter Knippertz, Erica Madonna, Sebastian Schemm, Bojan ŠKerlak, and HeINI Wernli

Climatologies of Eulerian and Lagrangian flow features are made openly available from ETH Zürich with monthly time resolution for research on seasonal and interannual atmospheric flow variability.

REANALYSES AND FEATURE-BASED CLIMATOLOGIES. For more than 20 years, reanalyses have become invaluable for a range of research activities, for example, for case studies of selected weather events, for driving regional climate simulations, and for global long-term investigations of specific aspects of the atmospheric flow, including the quantification of trends and interannual variability. Feature-based applications focus on a specific flow feature, which then allows determining its climatological frequency, geographical pattern, and temporal variability.

Early feature-based identification schemes have been developed for cyclones (e.g., Lambert 1988; Nielsen and Dole 1992; Hodges 1994), fronts (Hewson 1998), warm conveyor belts (i.e., strongly ascending airstreams in extratropical cyclones; Eckhardt et al. 2004), and jet streams (Koch et al. 2006). These and many more pioneering studies indicated the large
AFFILIATIONS: SPRENGER, BINDER, GRAF, GRAMs, ŠKERLAK, AND WERNLIInstitute for Atmosphere and Climate Science, ETH Zürich, Zurich, Switzerland; FRAGKOULIDIS-Institute for Atmosphere and Climate Science, ETH Zürich, Zurich, Switzerland, and Institute for Atmospheric Physics, University of Mainz, Mainz, Germany; CROCI-MASPOLI-Federal Office of Meteorology and Climatology MeteoSwiss, Zurich, Switzerland; KNIPPERTZ-Institute of Meteorology and Climate Research, Karlsruhe Institute of Technology, Karlsruhe, Germany; MadonNA AND SCHEMm—-Institute for Atmosphere and Climate Science, ETH Zürich, Zurich, Switzerland, and Geophysical Institute, University of Bergen, and Bjerknes Centre for Climate Research, Bergen, Norway
CORRESPONDING AUTHOR: Michael Sprenger, michael.sprenger@env.ethz.ch

The abstract for this article can be found in this issue, following the table of contents. DOI:10.II75/BAMS-D-I5-00299.I

A supplement to this article is available online (I0.II75/BAMS-D-I5-00299.2)

In final form 23 December 2016

C2017 American Meteorological Society

For information regarding reuse of this content and general copyright information, consult the AMS Copyright Policy. 
TABLE I. Short description of Eulerian (in blue) and Lagrangian (in orange) flow features and references that provide further details about the algorithms. The online supplement contains a table with all fields available for each of the features, as well as more details about the identification of extratropical cyclones and PV streamers and about updates since the original publications.

Upper-level jet streams

Extratropical cyclones (and anticyclones)

Fronts

PV cutoffs

PV streamers

Tropopause folds

Warm conveyor belts (WCBs)

Tropical moisture exports (TMEs)

Stratospheretroposphere exchange (STE)
Regions where the vertically averaged horizontal wind speed between 100 and $500 \mathrm{hPa}$ exceeds $30 \mathrm{~m} \mathrm{~s}^{-1}$.

Regions delimited by the outermost closed sea level pressure (SLP) contour enclosing one or several local SLP minima (or maxima in the case of anticyclones).

Regions where the horizontal gradient of equivalent potential temperature on $850 \mathrm{hPa}$ exceeds $4 \mathrm{~K}(100 \mathrm{~km})^{-1}$.

Regions where the negative anomaly of vertically averaged $\mathrm{PV}$ between 150 and $500 \mathrm{hPa}$ exceeds - I.3 PVU

( I PVU $\left.=10^{-6} \mathrm{~K} \mathrm{~kg}^{-1} \mathrm{~m}^{2} \mathrm{~s}^{-1}\right)$ and persists over at least 5 days.

Anomalies are calculated as deviations from the monthly climatology of vertically averaged PV.

Structures of stratospheric air ( $|\mathrm{PV}|>2$ PVU) that are detached from the main stratospheric body on a specific isentropic surface.

Filaments of stratospheric air on an isentropic surface, where the surrounding \pm 2 -PVU contour fulfills certain geometric criteria.

Regions where a vertical profile intersects the dynamical tropopause three times.

Air parcel trajectories ascending more than $600 \mathrm{hPa}$ in 2 days from the boundary layer to the upper troposphere near an extratropical cyclone. WCB frequencies result from gridding the trajectory positions in the middle of the 2-day ascent.

7-day air parcel trajectories originating in the tropics (i.e., within $20^{\circ} \mathrm{S}-20^{\circ} \mathrm{N}$ ) and with a horizontal moisture flux $>100 \mathrm{~g} \mathrm{~kg}^{-1} \mathrm{~m} \mathrm{~s}^{-1}$ poleward of $35^{\circ}$ latitude. TME frequencies result from gridding the 6-hourly trajectory positions during the first 5 days.

9-day air parcel trajectories crossing the dynamical tropopause with a residence time of at least 2 days on each side of the tropopause. STE frequencies result from gridding the positions where the trajectories cross the tropopause.
Koch et al. (2006)

Wernli and Schwierz (2006)

Jenkner et al. (2010);

Schemm et al. (2015)

Schwierz et al. (2004a);

Croci-Maspoli et al. (2007)

Wernli and Sprenger (2007)

Wernli and Sprenger (2007)

Sprenger et al. (2003);

Škerlak et al. (20I5)

Madonna et al. (2014)

Knippertz and Wernli (2010)

Škerlak et al. (2014) potential of this approach, which can (i) be applied to large datasets and yield frequency maps (see Fig. 1) and trend estimates of specific flow phenomena, (ii) be used to validate specific aspects of climate simulations (e.g., do they capture the structure of intense extratropical cyclones?; cf. Catto et al. 2010), and (iii) provide novel insight into the dynamics of the features under consideration. For instance, in recent years, research on cyclones and fronts and their interaction and link to (extreme) precipitation benefited substantially from the development of sophisticated algorithms to identify, track, and relate these flow features (e.g., Hewson and Titley 2010; Pfahl and Wernli 2012; Catto and Pfahl 2013; Papritz et al. 2014; Chang et al. 2015; Hewson and Neu 2015; Schemm and Sprenger 2015).

To enable further research applications using feature climatologies, we offer open access to global frequency fields of several flow features calculated with
European Centre for Medium-Range Weather Forecasts (ECMWF) interim reanalyses (ERA-Interim; Dee et al. 2011) via the web portal http://eraiclim.ethz.ch. After a straightforward registration procedure, this web page offers monthly mean fields for currently 15 types of flow features in the form of Network Common Data Format (netCDF) files or direct visualization (in PNG or PDF format). The supplement contains step-by-step instructions about how to access the data and a table of all available fields, which are currently available up to October 2016 (see http:// dx.doi.org/I0.II75/BAMS-D-I5-00299.2). They will be regularly extended into the future once a year as long as ERA-Interim data will be produced. Later, it is intended to continue these monthly feature climatologies with the new generation of ERA5 (Hersbach and Dee 2016). Feature data at higher temporal resolution can be obtained from the authors on request. 
The next section briefly introduces the algorithms used for the feature identification. Most climatologies are based on Eulerian gridpoint diagnostics and three are Lagrangian, that is, based upon very large sets of air parcel trajectories. Then, boreal winter climatologies are presented for several features and two example applications illustrate the use of the monthly mean fields. These applications identify the most anomalous Northern Hemisphere winter since 1979 and investigate flow feature anomalies related to drought conditions in the western United States.

\section{CALCULATION OF THE CLIMATOLOGI-}

CAL FIELDS. Temperature, specific humidity, and wind fields of ERA-Interim were used on the original 60 model levels and horizontally interpolated to a regular grid with $1^{\circ} \times 1^{\circ}$ resolution. Secondary variables such as potential temperature and potential vorticity (PV) were calculated on this grid. A first set of non-feature-based climatologies was calculated by averaging 6-hourly Eulerian fields. These fields include pressure at the dynamical tropopause (cf. Hoskins et al. 1985) and Eady growth rate evaluated at $700 \mathrm{hPa}$, which equals the ratio of the vertical wind shear and static stability and indicates the potential for linear growth of baroclinic disturbances (e.g., Lindzen and Farrell 1980).

Table 1 briefly introduces the main Eulerian and Lagrangian features. Eulerian features include, for example, jet streams, cyclones, and fronts. They are identified from a specific, typically $2 \mathrm{D}$ field, through the application of one or several thresholds and/or geometric criteria. For certain features (cyclones and PV streamers) the detailed identification of a set of contours is required. For every feature, application of the specific criteria yields 6-hourly 2D binary fields with the value 1 at grid points that meet the criteria and 0 at grid points that do not. Monthly (or longer term) climatological fields are then obtained by temporally averaging the binary fields. A climatological value of, for example, 0.3 indicates that at this grid point the considered feature occurs at $30 \%$ of all time steps.

For the Lagrangian flow features, large numbers of kinematic air parcel trajectories are computed with the Lagrangian analysis tool LAGRANTO (Wernli and Davies 1997; Sprenger and Wernli 2015). These trajectories are based upon the threedimensional ERA-Interim wind field, available every $6 \mathrm{~h}$ on the $1^{\circ} \times 1^{\circ}$ grid, which cannot account for the rapid vertical motion in convective clouds but is suitable for slantwise large-scale transport. The global identification of these features is computationally demanding, as up to about 800,000 trajectories need to be calculated every $6 \mathrm{~h}$ before selection criteria can be applied to identify the desired features. A gridding procedure is then employed to project the trajectory positions onto a regular grid with $1^{\circ} \times 1^{\circ}$ resolution, and a binary field is constructed such that the value 1 indicates that at least one trajectory is present in the grid column. As for the Eulerian features, temporal averaging indicates the percentage of time steps when a trajectory-based feature is present in the vertical column represented by a certain grid point.

For several feature categories, different fields are available, for instance, for fronts, fields of front frequency, propagation velocity, and strength. A complete table with the currently available fields in all categories can be found in the supplement.

\section{NORTHERN HEMISPHERE WINTER CLI-} MATOLOGIES. To illustrate the potential of this dataset for climatological analyses, Fig. 1 shows mean fields of tropopause pressure, Eady growth rate, and the three Lagrangian and a selection of the Eulerian features for the 1979-2014 Northern Hemisphere winters.

Tropopause pressure (Fig. 1a) increases toward the pole, and the field shows clear deviations from zonal symmetry related to stationary waves. The tropopause is lowest over eastern Canada and the western Pacific. Steep gradients in tropopause pressure are found at the entrance of the North Atlantic and North Pacific storm tracks and over northern Africa, that is, in regions with very high jet frequencies (nearly $100 \%$ over the North Pacific, $80 \%$ over the North Atlantic, and 90\% over Africa; Fig. 1c). This close relationship between jet frequencies and tropopause pressure gradients is due to the link between isentropic PV gradients and wind speed (e.g., Schwierz et al. 2004b). In extratropical regions with high jet frequencies, Eady growth rates are also enhanced (Fig. 1b), as expected from thermal wind balance.

Extratropical cyclone frequencies (Fig. 1d) are highest in the North Pacific and North Atlantic near $60^{\circ} \mathrm{N}$, in particular between Greenland and Iceland, where a peak value of $45 \%$ is reached. Because cyclones typically propagate toward the northeast across a region with enhanced Eady growth rate (where they intensify), it is plausible that cyclone frequency maxima occur northeast of regions with enhanced Eady growth rates (Fig. 1b). Additional frequency maxima (20\%) occur in the Mediterranean region, often related to Alpine lee cyclogenesis, and in the lee 
a) tropopause pressure

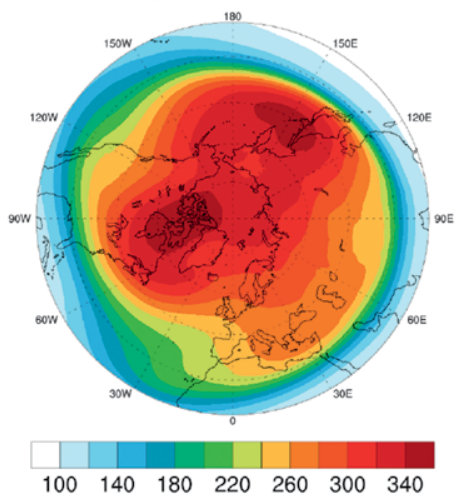

d)

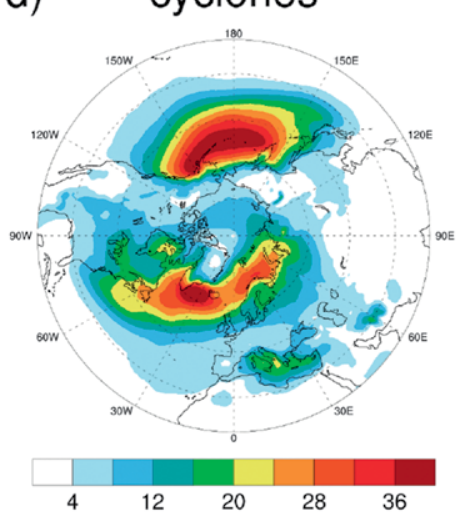

g) downward STE

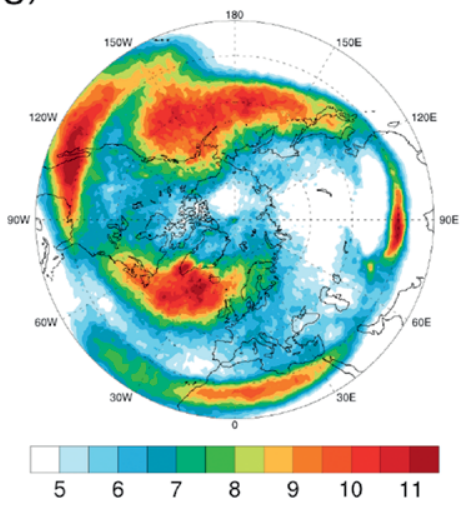

b) Eady growth rate

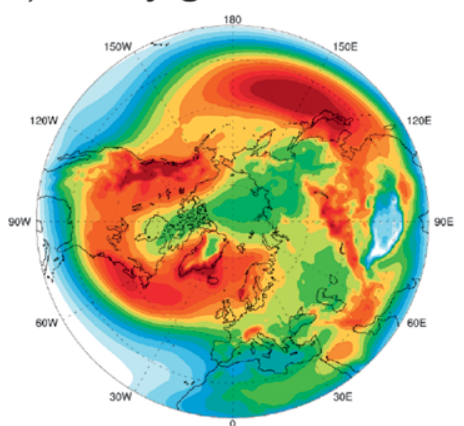

$\begin{array}{llllllll}0.3 & 0.4 & 0.5 & 0.6 & 0.7 & 0.8 & 0.9 & 1\end{array}$

e)

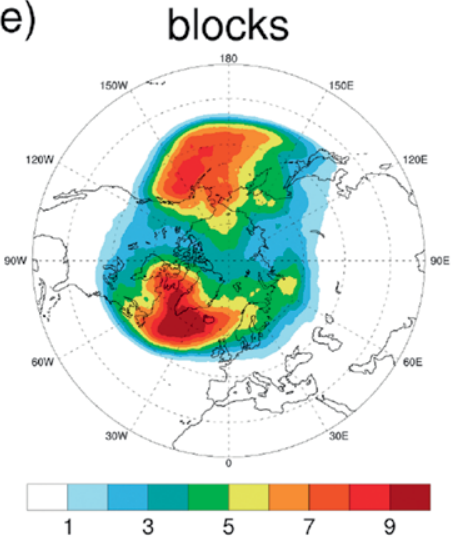

h)

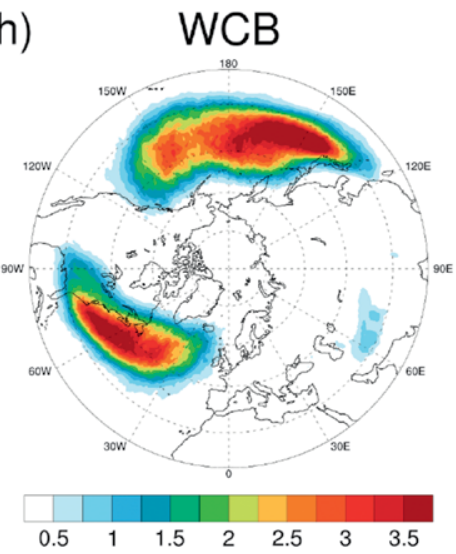

c) jets

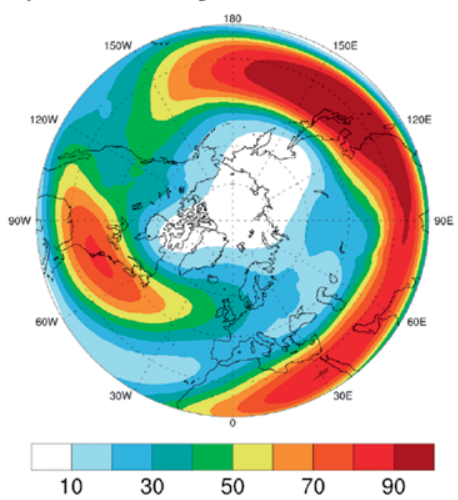

f) stratospheric PV cutoffs

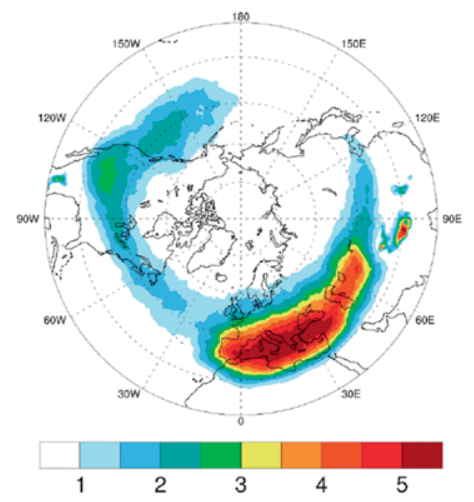

i)

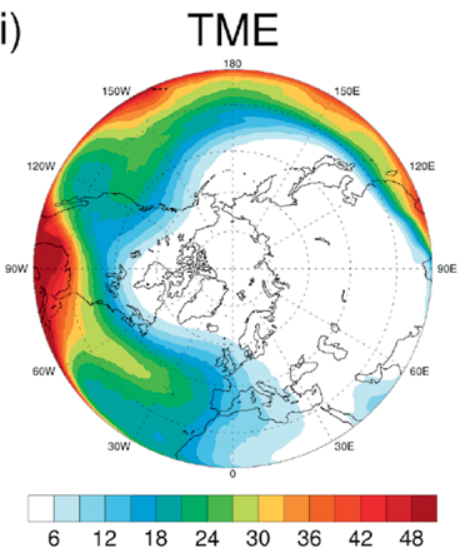

Fig. I. Climatological boreal winter fields in the Northern Hemisphere for the period 1979-20I4 of (a) tropopause pressure (hPa), (b) Eady growth rate $\left(d^{-1}\right),(c) 30 \mathrm{~m} \mathrm{~s}^{-1}$ jet frequency (\%), (d) cyclone frequency (\%), (e) blocking frequency (\%), (f) frequency of stratospheric PV cutoffs on $310 \mathrm{~K}(\%)$, (g) frequency of downward STE trajectories (\%), (h) frequency of WCB trajectories (\%), and (i) frequency of TME trajectories (\%).

of other mountains (e.g., $10 \%$ in the lee of the Rocky Mountains). Cyclone frequencies broadly match the ascending parts of warm conveyor belts (WCBs; Fig. 1h). Two pronounced WCB maxima span the North Atlantic and North Pacific basins, with peak values of $7 \%$ above the Gulf Stream and Kuroshio. Compared to the cyclone frequency maxima, the WCB maxima are farther equatorward, consistent with the fact that WCBs are strongest during the period of cyclone intensification. Mediterranean cyclones are typically lacking WCBs.

Another Lagrangian feature, sometimes associated with cyclones and related to the concept of atmospheric rivers (e.g., Ralph et al. 2004; Dacre et al. 2015), are tropical moisture exports (TMEs; Fig. 1i). The most striking "tongues" of high TME frequencies into the extratropics are directed toward the west coasts of the United States and Europe, 
respectively. They bring large amounts of moisture to these regions, a fact reflected by a specific terminology for this meteorological situation in the western United States (Pineapple Express; e.g., Higgins et al. 2000).

For several features discussed so far, frequency maxima occur over the North Atlantic and North Pacific storm-track regions. This is also true for downward stratosphere-troposphere exchange (STE), that is, transport from the stratosphere into the troposphere (Fig. 1g). Two distinct bands of strong STE originate as narrow strips at the western oceanic boundaries and broaden to the east. The frequencies are $\sim 10 \%$ over the oceans, a factor of $2-3$ larger than over the continents. In addition, enhanced values of $\sim 10 \%$ occur in a subtropical band near $30^{\circ} \mathrm{N}$, with three distinct local maxima (northern Africa, south of the Himalayas, near the North American west coast). The existence of distinct extratropical and subtropical maxima indicates that two different physical processes are at work. Whereas extratropical cyclones (Fig. 1d) are important for STE north of $30^{\circ} \mathrm{N}, \mathrm{PV}$ cutoffs resulting from Rossby wave breaking are key in the subtropics. The PV cutoff climatology on $310 \mathrm{~K}$ (Fig. 1f) shows frequency maxima over the Mediterranean (6\%) and North America, whose southern boundaries coincide with regions of strong downward STE (Fig. 1g). Finally, Fig. 1e shows the frequency of atmospheric blocks, exhibiting a clear maximum in the North Atlantic (10\%) and a slightly weaker one in the North Pacific (8\%), that is, in the jet exit regions, respectively.

As a final point, we stress that special care is required if mean patterns (as shown in Fig. 1) are compared to deduce "causal links," because spatial agreement does not imply simultaneous occurrence of the features. For instance, assuring that the frequency peaks of cyclones and downward STE near the southern tip of Greenland (Figs. 1d,g) are dynamically related requires a more detailed analysis considering 6-hourly fields (Reutter et al. 2015). On the other hand, it is obvious that spatial agreement between the frequency maxima of cyclones and blocks in the same region (Figs. 1d,e) does not imply that they occur simultaneously.
THE UNUSUAL NORTHERN HEMISPHERIC WINTER OF 2009/IO. Several studies reported the unusual character of the 2009/10 Northern Hemisphere winter. Harnik et al. (2014) emphasized that the North Atlantic jet in winter 2009/10 was unusually zonal, leading to a merging of the North Atlantic and the African jets. The indices of the Arctic Oscillation (AO) and El Niño-Southern Oscillation were strongly negative and moderately positive, respectively (e.g., Cohen et al. 2011). If considering the so-called central Pacific El Niño, then this winter was the strongest since 1979 (Ratnam et al. 2012). In addition, the winter was characterized by a distorted polar vortex, an easterly phase of the quasi-biennial oscillation, a minimum of solar activity, and an anomalous planetary wave activity leading to two stratospheric sudden warming events (e.g., Fereday et al. 2012). Thorpe et al. (2013) investigated the quality of ECMWF forecasts and found particularly high values of the $500-\mathrm{hPa}$ geopotential height anomaly correlation in this winter. They showed that this was related to very strong deviations of the flow from climatology. Jung et al. (2011) concluded that internal atmospheric dynamical processes were the definitive driver of the anomalies in winter 2009/10 and that the forcing by El Niño, the quasi-biennial oscillation, and reduced solar insolation was not capable of reproducing the observed record negative AO. Similar conclusions about the primary role of natural variability, related to the dynamics of jet streams, Rossby waves, cyclones, and blocks, were reported for the anomalous winter 2013/14 (Davies 2015) and spring 2012 with extreme warmth over the United States (Dole et al. 2014). The following application illustrates the potential of our dataset for studying interannual variability of the atmospheric flow.

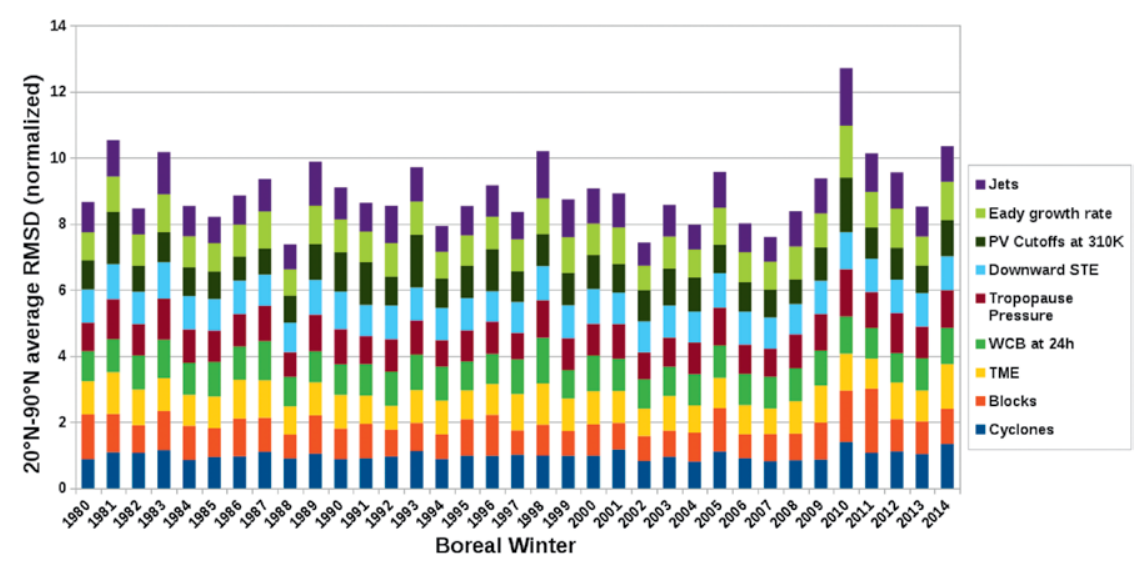

FIG. 2. Stacked-bar chart of the integrated anomalies of the 1979/80-2013/14 winters in the region $20^{\circ}-90^{\circ} \mathrm{N}$. Each color corresponds to the normalized root-mean-square deviation of the respective field (see legend) from its climatology. 
The most anomalous Northern Hemispheric winter in the time period from 1979/80 to 2013/14 is identified by calculating, for the features shown in Fig. 1 and for each winter, the root-mean-square deviation of the seasonal fields from their long-term climatology. All anomalies are normalized by the 35 -yr winter mean root-mean-square deviation of the respective field. (Figures ES8 and ES9 in the online supplement provide additional information about the monthly anomaly time series for the different features and their correlations. Figure ES4 portrays geographical maps of the features' interannual variability.)

Figure 2 shows a stacked-bar chart of the normalized anomalies of the nine fields evaluated in the region from $20^{\circ}$ to $90^{\circ} \mathrm{N}$. The winter $2009 / 10$ clearly stands out. The winters $1980 / 81$ and 2013/14 were a) tropopause pressure

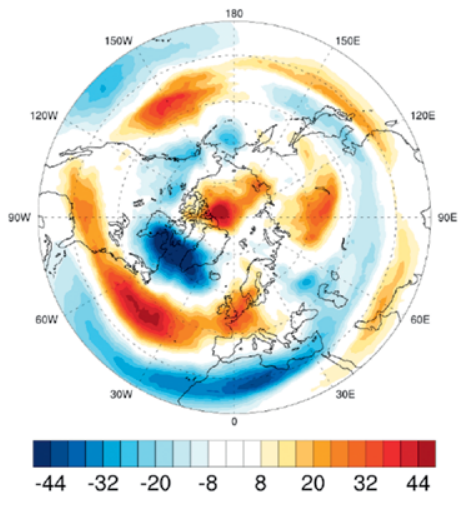

d)

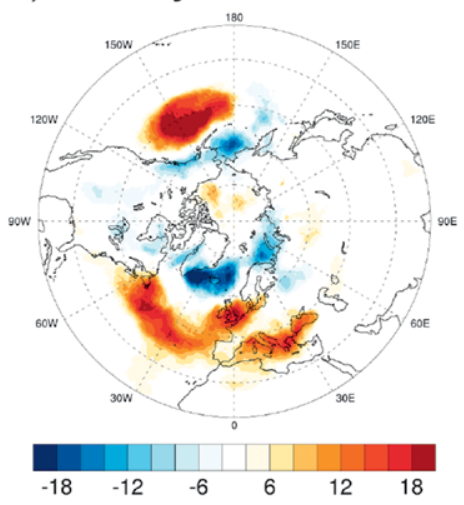

g) downward STE

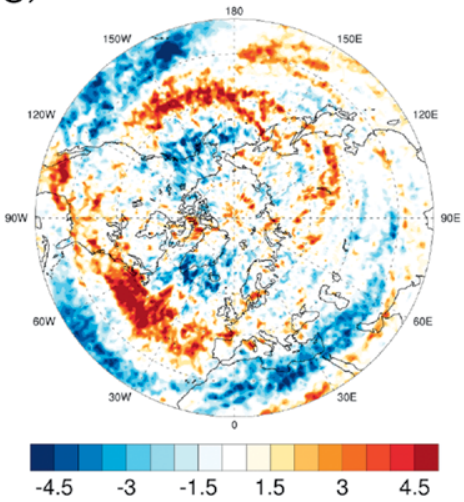

b) Eady growth rate

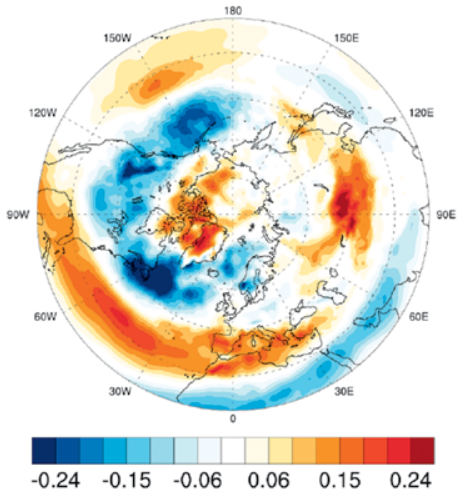

e)

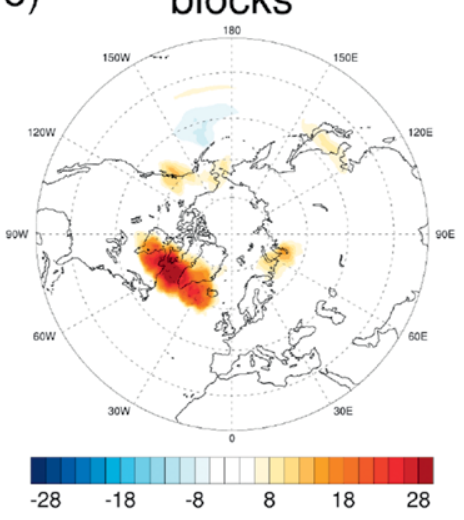

h)

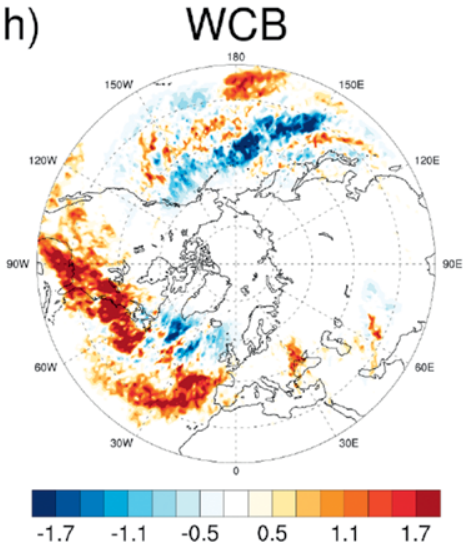

c) jets

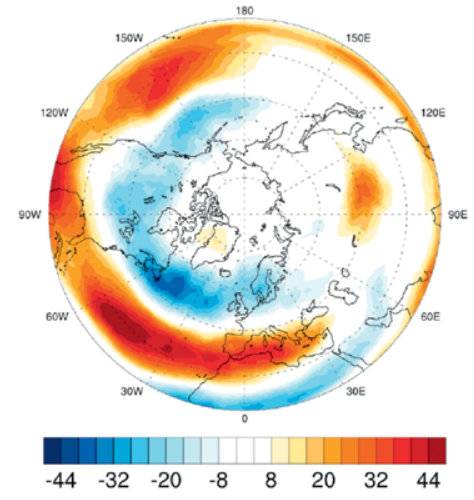

f) stratospheric PV cutoffs

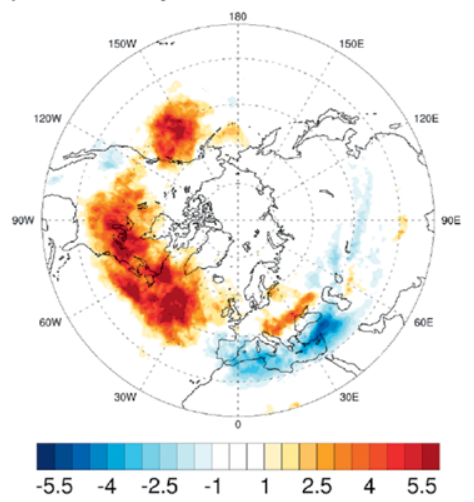

i)

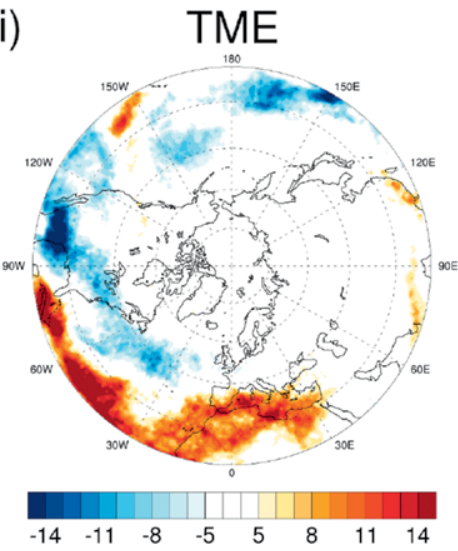

FIg. 3. Seasonal anomalies of all fields shown in Fig. I for the winter 2009/I0: (a) tropopause pressure (hPa), (b) Eady growth rate (day $\left.{ }^{-1}\right)$, (c) jet frequency (\%), (d) cyclone frequency (\%), (e) blocking frequency (\%), (f) frequency of stratospheric PV cutoffs on $310 \mathrm{~K}(\%)$, (g) frequency of downward STE trajectories (\%), (h) frequency of WCB trajectories (\%), and (i) frequency of TME trajectories (\%). Blue and red colors indicate negative and positive anomalies, respectively. 
also strongly anomalous, as well as the strong El Niño winters of 1982/83 and 1997/98 (despite excluding the tropics from the considered domain). Winter 2009/10 was the most anomalous for tropopause pressure, jet streams, Eady growth rate, cyclones, and stratospheric PV cutoffs; was the second-most anomalous winter for blocks; and ranked third, fourth, and eighth for downward STE, WCBs, and TMEs, respectively. This points to an interesting consistency in terms of the seasonal deviation from climatology between several fields.

This is investigated further with Fig. 3, which presents the winter 2009/10 frequency anomalies of the features considered in Fig. 1. Most fields show larger anomalies in the Western Hemisphere, with overall quite consistent anomaly patterns. In terms of standard deviation of interannual variability (Fig. ES4), most anomalies exceed $3 \sigma$ in some regions. The jet streams in the North Pacific and North Atlantic are strongly shifted toward the equator (Fig. 3c). The Eady growth rate (Fig. $3 \mathrm{~b}$ ) shows a very similar, although slightly more noisy, anomaly pattern, indicating that the variability of the lower-tropospheric baroclinicity (measured by the Eady growth rate) is important for the variability of the upper-tropospheric jet frequency. These anomalies are consistent with the tropopause pressure anomaly pattern (Fig. 3a), which shows, for example, near Newfoundland, a dipole indicating a flatter tropopause and consequently reduced jet stream frequency. The southward shift of low-tropospheric baroclinicity is consistent with a southward shift of the main cyclone activity in both the North Pacific and North Atlantic and enhanced cyclone activity in the Mediterranean (Fig. 3d). In midlatitudes, anomalies of tropopause pressure and cyclone frequency agree well (Figs. 3a,d), indicating the relevance of tropopause dynamics for extratropical cyclones. A positive blocking anomaly is found over Greenland (Fig. 3e), a region with reduced cyclone activity and an elevated tropopause (Fig. 3a). Regions with enhanced cyclone frequencies are also characterized by an enhanced formation of PV cutoffs (Fig. 3f) and downward STE (Fig. 3g). WCB frequency is enhanced along the U.S. East Coast (Fig. $3 \mathrm{~h}$ ), consistent with the positive cyclone anomaly downstream of Newfoundland and potentially relevant for the positive Greenland blocking anomaly (Pfahl et al. 2015). Finally, the TME anomaly pattern (Fig. 3i) appears to be loosely related to the others, consistent with the fact that TMEs are not exceptionally anomalous in this winter.

CALIFORNIA DROUGHTS. The second example application of our seasonal flow feature dataset demonstrates its potential for regional analyses by addressing dry winters in the western United States. Since 1979, California has been affected by several long-lived and severe droughts, and two of them are briefly discussed here: the first from 1986 to 1992 (e.g., Roos 1994; Bell and Basist 1994) and the second starting in 2012 and persisting into 2016 (e.g., Seager et al. 2015). According to the National Oceanic and Atmospheric Administration (NOAA)/National Centers for Environmental Information (NCEI) statewide precipitation data (www.ncdc.noaa.gov/cag/time-series/us), California a) precipitation

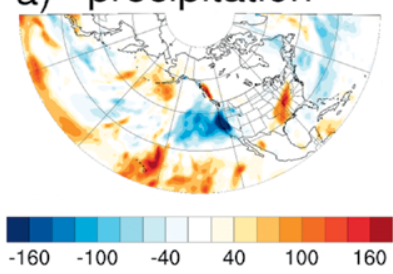

b)
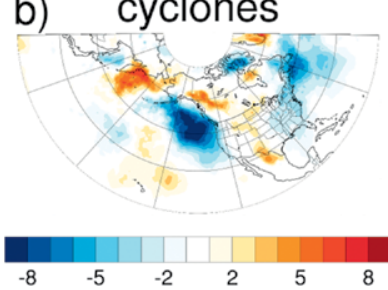

c)

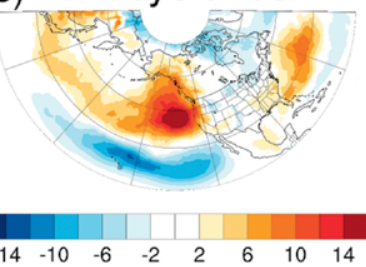

d)

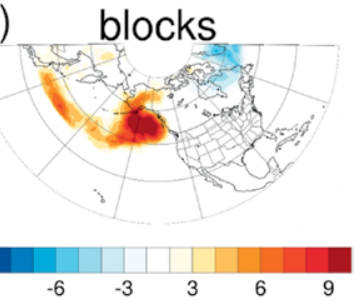

e) precipitation

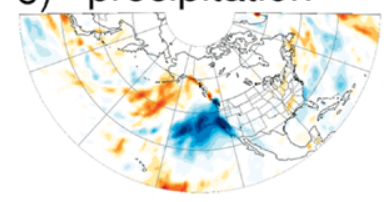

f) cyclones

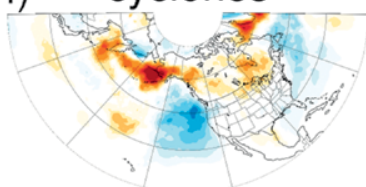

g)

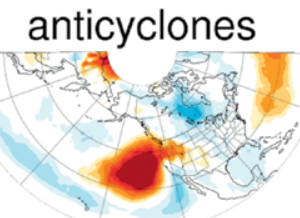

h)

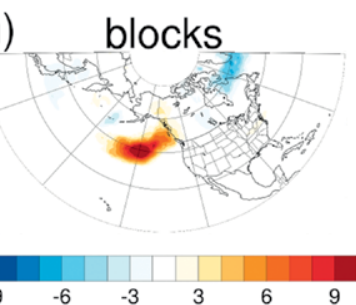

Fig. 4. Seasonal anomalies of (from left to right) precipitation $(\mathrm{mm})$, cyclone frequency (\%), anticyclone frequency (\%), and blocking frequency (\%) for (a)-(d) the 1988/89-1990/91 winters and (e)-(h) the 2011/12-2013/14 winters. Blue and red colors indicate negative and positive anomalies, respectively. 
receives more than $50 \%$ of its annual precipitation during the three winter months on average. Therefore, winter precipitation in California and, as a result, the water shortage of the following months are very sensitive to slight deviations in the position and strength of the North Pacific storm track. The three winters of 1988/89-1990/91 and 2011/12-2013/14, respectively, were characterized by extremely low precipitation (Figs. 4a,e) and thus strongly contributed to the buildup of the respective droughts.

For both periods, the precipitation anomalies (Figs. $4 \mathrm{a}, \mathrm{e}$ ) coincide with negative anomalies of cyclone frequency (Figs. 4b,f; see also Chang et al. 2015). The cyclones in these winters follow more poleward tracks. However, interestingly, the strongest feature anomalies are found for surface anticyclones in the eastern North Pacific between $20^{\circ}$ and $50^{\circ} \mathrm{N}$. For cyclones, the peak frequency reduction by about $10 \%$ off the U.S. West Coast corresponds to almost an absence of cyclones in this area (cf. Fig. 1d), and for anticyclones the peak frequency increases even by $23 \%$. Some surface anticyclones appear to be related to blocking events (Figs. $4 \mathrm{~d}$,h), which by definition are most sensitive to the upper-tropospheric flow. In this region the climatological blocking frequency is moderate $(<10 \%$, Fig. 1e), and therefore an increase of their frequency by $8 \%-12 \%$ during the considered dry seasons is substantial. Because of the relative long duration of blocks, such a frequency increase corresponds to 1-2 additional long-lasting individual events during one winter. Interestingly, TME frequency anomalies near the U.S. West Coast were only slightly negative in the earlier drought period and close to zero for the later period (not shown), indicating that the reduction of moisture transport from the tropics is surprisingly modest during severe droughts. This brief analysis confirms that the frequency of near-upstream synoptic weather systems in winter is relevant for precipitation in California.

\section{CONCLUSIONS AND WEB INTERFACE.}

A set of different climatologies of atmospheric flow features has been presented, all developed in previous independent studies and applied here for the first time to the same state-of-the-art reanalysis dataset (ERA-Interim, 1979-2014). These seasonal feature climatologies provide weather-system-specific insight into regional, hemispheric, or global long-term flow anomalies. We presented two illustrative examples of how these fields can be valuable for research on atmospheric variability on seasonal to decadal times. Whereas these examples focused on the firstorder consistency between seasonal anomalies, the dataset also offers the option to consider higherorder effects (e.g., are there specific seasons when cyclone frequencies are increased in an ocean basin but WCB frequencies are not?). The web interface http://eraiclim.ethz.ch provides open access to monthly, seasonal, and longer-term averages from this flow feature climatology, and selected fields at higher resolution are available from the authors upon request. The ERA-Interim-based dataset will be continuously extended, and, after the transition to the new ERA5 (Hersbach and Dee 2016), we intend to produce a similar set of climatologies for this higherresolution reanalysis.

ACKNOWLEDGMENTS. We very much appreciate the constructive suggestions by the Editor, Brian Mapes, and two anonymous reviewers, which improved the presentation of our results. We are grateful to ECMWF and MeteoSwiss for granting access to the full-resolution ERA-Interim data and acknowledge funding contributions from the Swiss National Science Foundation (Projects 200020_146834 and 200021_130079, H.B. and E.M., respectively) and from the German Research Foundation ("Waves to Weather" Transregional Collaborative Research Center SFB/TRR 165, G.F. and P.K., and "PANDOWAE" Research Unit FOR896, C.M.G.).

\section{REFERENCES}

Bell, G. D., and A. N. Basist, 1994: The global climate of December 1992-February 1993. Part I: Warm ENSO conditions continue in the Tropical Pacific; California drought abates. J. Climate, 7, 1581-1605, doi:10.1175/1520-0442(1994)007<1581:TGCODP $>2.0 . \mathrm{CO} ; 2$.

Catto, J. L., and S. Pfahl, 2013: The importance of fronts for extreme precipitation. J. Geophys. Res. Atmos., 118, 10791-10 801, doi:10.1002/jgrd.50852.

- L. C. Shaffrey, and K. I. Hodges, 2010: Can climate models capture the structure of extratropical cyclones? J. Climate, 23, 1621-1635, doi:10.1175 /2009JCLI3318.1.

Chang, E. K. M., C. Zheng, P. Lanigan, A. M. W. Yau, and J. D. Neelin, 2015: Significant modulation of variability and projected change in California winter precipitation by extratropical cyclone activity. Geophys. Res. Lett., 42, 5983-5991, doi:10.1002/2015GL064424.

Cohen, J., J. Foster, M. Barlow, K. Saito, and J. Jones, 2011: Winter 2009-2010: A case study of an extreme Arctic Oscillation event. Geophys. Res. Lett., 37, L17707, doi:10.1029/2010GL044256.

Croci-Maspoli, M., C. Schwierz, and H. C. Davies, 2007: A multifaceted climatology of atmospheric blocking 
and its recent linear trend. J. Climate, 20, 633-649, doi:10.1175/JCLI4029.1.

Dacre, H. F., P. A. Clark, O. Martinez-Alvarado, M. A. Stringer, and D. A. Lavers, 2015: How do atmospheric rivers form? Bull. Amer. Meteor. Soc., 96, 1243-1255, doi:10.1175/BAMS-D-14-00031.1.

Davies, H. C., 2015: Weather chains during the 2013/2014 winter and their significance for seasonal prediction. Nat. Geosci., 8, 833-837, doi:10.1038/ngeo2561.

Dee, D. P., and Coauthors, 2011: The ERA-Interim reanalysis: Configuration and performance of the data assimilation system. Quart. J. Roy. Meteor. Soc., 137, 553-597, doi:10.1002/qj.828.

Dole, R. M., and Coauthors, 2014: The making of an extreme event: Putting the pieces together. Bull. Amer. Meteor. Soc., 95, 427-440, doi:10.1175/BAMS -D-12-00069.1.

Eckhardt, S., A. Stohl, H. Wernli, P. James, C. Forster, and N. Spichtinger, 2004: A 15-year climatology of warm conveyor belts. J. Climate, 17, 218-237, doi:10.1175/1520-0442(2004)017<0218:AYCOWC $>2.0$.CO;2.

Fereday, D. R., A. Maidens, A. Arribas, A. A. Scaife, and J. R. Knight, 2012: Seasonal forecasts of northern hemisphere winter 2009/10. Environ. Res. Lett., 7, 034031, doi:10.1088/1748-9326/7/3/034031.

Harnik, N., E. Galanti, O. Martius, and O. Adam, 2014: The anomalous merging of the African and North Atlantic jet streams during the Northern Hemisphere winter of 2010. J. Climate, 27, 7319-7334, doi:10.1175 /JCLI-D-13-00531.1.

Hersbach, H., and D. Dee, 2016: ERA5 reanalysis is in production. ECMWF Newsletter, No. 147, ECMWF, Reading, United Kingdom, 7. [Available online at www.ecmwf.int/sites/default/files /elibrary/2016/16299-newsletter-no147-spring-2016 .pdf.]

Hewson, T. D., 1998: Objective fronts. Meteor. Appl., 5, 37-65, doi:10.1017/S1350482798000553.

— typing and tracking of the complete life-cycles of cyclonic features at high spatial resolution. Meteor. Appl., 17, 355-381, doi:10.1002/met.204.

- - and U. Neu, 2015: Cyclones, windstorms and the IMILAST project. Tellus, 67A, 27128, doi:10.3402 /tellusa.v67.27128.

Higgins, R. W., J.-K. E. Schemm, W. Shi, and A. Leetma, 2000: Extreme precipitation events in the western United States related to tropical forcing. J. Climate, 13, 793-820, doi:10.1175/1520-0442(2000)013<0793:EP EITW >2.0.CO;2.

Hodges, K. I., 1994: A general method for tracking analysis and its application to meteorological data.
Mon. Wea. Rev., 122, 2573-2586, doi:10.1175/1520 -0493(1994)122<2573:AGMFTA>2.0.CO;2.

Hoskins, B. J., M. E. McIntyre, and A. W. Robertson, 1985: On the use and significance of isentropic potential vorticity maps. Quart. J. Roy. Meteor. Soc., 111, 877-946, doi:10.1002/qj.49711147002.

Jenkner, J., M. Sprenger, C. Schwierz, S. Dierer, and D. Leuenberger, 2010: Detection and climatology of fronts in a high-resolution model reanalysis over the Alps. Meteor. Appl., 17, 1-18, doi:10.1002/met.142.

Jung, T., F. Vitart, L. Ferranti, and J. J. Morcrette, 2011: Origin and predictability of the extreme negative NAO winter of 2009/10. Geophys. Res. Lett., 38, L07701, doi:10.1029/2011GL046786.

Knippertz, P., and H. Wernli, 2010: A Lagrangian climatology of tropical moisture exports to the Northern Hemispheric extratropics. J. Climate, 23, 987-1003, doi:10.1175/2009JCLI3333.1.

Koch, P., H. Wernli, and H. C. Davies, 2006: An eventbased jet-stream climatology and typology. Int. J. Climatol., 26, 283-301, doi:10.1002/joc.1255.

Lambert, S. J., 1988: A cyclone climatology of the Canadian Climate Centre general circulation model. J. Climate, 1, 109-115, doi:10.1175/1520-0442 (1988)001<0109:ACCOTC $>2.0 . C O ; 2$.

Lindzen, R. S., and B. Farrell, 1980: A simple approximate result for the maximum growth-rate of baroclinic instabilities. J. Atmos. Sci., 37, 1648-1654, doi:10.1175/1520-0469(1980)037<1648:ASARFT >2 .0.CO;2.

Madonna, E., H. Wernli, H. Joos, and O. Martius, 2014: Warm conveyor belts in the ERA-Interim dataset (1979-2010). Part I: Climatology and potential vorticity evolution. J. Climate, 27, 3-26, doi:10.1175 /JCLI-D-12-00720.1.

Nielsen, J. W., and R. M. Dole, 1992: A survey of extratropical cyclone characteristics during GALE. Mon. Wea. Rev., 120, 1156-1167, doi:10.1175/1520 -0493(1992)120<1156:ASOECC >2.0.CO;2.

Papritz, L., S. Pfahl, I. Rudeva, I. Simmonds, H. Sodemann, and H. Wernli, 2014: The role of extratropical cyclones and fronts for Southern Ocean freshwater fluxes. J. Climate, 27, 6205-6224, doi:10.1175/JCLI -D-13-00409.1.

Pfahl, S., and H. Wernli, 2012: Quantifying the relevance of cyclones for precipitation extremes. J. Climate, 25, 6770-6780, doi:10.1175/JCLI-D-11-00705.1.

- C. Schwierz, M. Croci-Maspoli, C. M. Grams, and H. Wernli, 2015: Importance of latent heat release in ascending air streams for atmospheric blocking. Nat. Geosci., 8, 610-615, doi:10.1038/ngeo2487.

Ralph, M. F., P. J. Neiman, and G. A. Wick, 2004: Satellite and CALJET aircraft observations of atmospheric 
rivers over the eastern North Pacific Ocean during the winter of 1997/98. Mon. Wea. Rev., 132, 1721-1745, doi:10.1175/1520-0493(2004)132<1721:SA $\mathrm{CAOO}>2.0 . \mathrm{CO} ; 2$.

Ratnam, J. V., S. K. Behera, Y. Masumoto, K. Takahashi, and T. Yamagata, 2012: Anomalous climatic conditions associated with the El Niño Modoki during boreal winter of 2009. Climate Dyn., 39, 227-238, doi:10.1007/s00382-011-1108-z.

Reutter, P., B. Škerlak, M. Sprenger, and H. Wernli, 2015: Stratosphere-troposphere exchange (STE) in the vicinity of North Atlantic cyclones. Atmos. Chem. Phys., 15, 10 939-10 953, doi:10.5194/acp-15-10939-2015.

Roos, M., 1994: Is the California drought over? Proc. 10th Annual Pacific Climate (PACLIM) Workshop, Pacific Grove, CA, USGS, 123-128.

Schemm, S., and M. Sprenger, 2015: Frontal-wave cyclogenesis in the North Atlantic - A climatological characterisation. Quart. J. Roy. Meteor. Soc., 141, 2989-3005, doi:10.1002/qj.2584.

— I. Rudeva, and I. Simmonds, 2015: Extratropical fronts in the lower troposphere-Global perspectives obtained from two automated methods. Quart. J. Roy. Meteor. Soc., 141, 1686-1698, doi:10.1002/qj.2471.

Schwierz, C., M. Croci-Maspoli, and H. C. Davies, 2004a: Perspicacious indicators of atmospheric blocking. Geophys. Res. Lett., 31, L06125, doi:10.1029/2003GL019341.

— S. Dirren, and H. C. Davies, 2004b: Forced waves on a zonally aligned jet stream. J. Atmos. Sci., 61, 73-87, doi:10.1175/1520-0469(2004)061<0073:FWO $\mathrm{AZA}>2.0 . \mathrm{CO} ; 2$.

Seager, R., M. Hoerling, S. Schubert, H. Wang, B. Lyon, A. Kumar, J. Nakamura, and N. Henderson, 2015: Causes of the 2011-14 California drought. J. Climate, 28, 6997-7024, doi:10.1175/JCLI-D-14-00860.1.
Škerlak, B., M. Sprenger, and H. Wernli, 2014: A global climatology of stratosphere-troposphere exchange using the ERA-Interim dataset from 1979 to 2011. Atmos. Chem. Phys., 14, 913-937, doi:10.5194/acp -14-913-2014.

—, M. Sprenger, S. Pfahl, E. Tyrlis, and H. Wernli, 2015: Tropopause folds in ERA-Interim: Global climatology and relation to extreme weather events. J. Geophys. Res. Atmos., 120, 4860-4877, doi:10.1002/2014JD022787.

Sprenger, M., and H. Wernli, 2015: The LAGRANTO Lagrangian analysis tool - version 2.0. Geosci. Model Dev., 8, 2569-2586, doi:10.5194/gmd-8-2569-2015.

-, M. Croci Maspoli, and H. Wernli, 2003: Tropopause folds and cross-tropopause transport: A global investigation based upon ECMWF analyses for the time period March 2000 till February 2001. J. Geophys. Res., 108, 8518, doi:10.1029/2002JD002587.

Thorpe, A., P. Bauer, L. Magnusson, and D. Richardson, 2013: An evaluation of recent performance of ECMWF's forecasts. ECMWF Newsletter, No. 137, ECMWF, Reading, United Kingdom, 15-18. [Available online at www.ecmwf.int/sites/default/files/elibrary/2013/14579 -newsletter-no137-autumn-2013.pdf.]

Wernli, H., and H. C. Davies, 1997: A Lagrangian-based analysis of extratropical cyclones. I: The method and some applications. Quart. J. Roy. Meteor. Soc., 123, 467-489, doi:10.1002/qj.49712353811.

- , and C. Schwierz, 2006: Surface cyclones in the ERA40 data set (1958-2001). Part I: Novel identification method and global climatology. J. Atmos. Sci., 63, 2486-2507, doi:10.1175/JAS3766.1.

—, and M. Sprenger, 2007: Identification and ERA15 climatology of potential vorticity streamers and cutoffs near the extratropical tropopause. J. Atmos. Sci., 64, 1569-1586, doi:10.1175/JAS3912.1. 